Departamento de Neurología. Clínica Las Condes, Santiago, Chile.

Recibido el 5 de mayo de 2016, aceptado el 22 de octubre de

2016.

Correspondencia:

Dr. Marcelo Miranda

Antonio Varas 175 of 302

marcelomirandac@gmail.com

\section{Paul Cézanne, el solitario padre de la pintura moderna}

\author{
MARCELO MIRANDA
}

\section{Paul Cézanne, the lonely precursor of modern painting}

Paul Cézanne is an acknowledged pioneer of modern painting. His work was poorly recognized during most of his solitary life. He progressively withdrew from people and society during his life, in part due to his introverted personality and a supreme effort to obtain a unique form of expression of his art, in which nature and its inner secrets played a pivotal role. In this review, we discuss aspects of his life and art, his pathological personal relationships and how they influenced his transcendental work.

(Rev Med Chile 2017; 145: 508-513)

Key words: Medicine in Art; Neural Pathways; Neurosciences; Paintings.
"Quisiera asombrar a París con una manzana".

Paul Cézanne, 1895

$\mathrm{P}$ aul Cézanne (1839-1906) permanece como uno de los más grandes, originales e influyentes pintores de la historia del arte. Según Pablo Picasso y Henri Matisse, "Cézanne es el padre de todos nosotros". En el desarrollo de su arte influyeron de manera fundamental aspectos de su vida familiar que determinaron su peculiar carácter. Cézanne nació en Aix-en-Provence, Francia, primer hijo de 3 que tuvieron Louis-Auguste Cézanne y Anne-Elisabeth Honorine Aubert. Cézanne tuvo 2 hermanas, Marie y Rose, de las cuales sólo Marie tuvo una estrecha relación con él ${ }^{1-4}$. Su padre, un comerciante de sombreros, llegó a ser un exitoso banquero. Ejerció una tiránica influencia sobre su hijo, oponiéndose a sus inquietudes artísticas. Paul Cézanne jamás pudo liberarse de la influencia paterna y dependió económicamente de él gran parte de su vida. Sólo en los últimos años, cuando ya había logrado cierto éxito, pudo independizarse en el aspecto material. Sin embargo, en el aspecto emocional, siempre estará presente la figura autoritaria del padre. Tal fue la influencia de su progenitor, que mantuvo oculta por más de 6 años su relación con Hortense Fiquet, la que fue su única relación amorosa. La conoció a los 30 años y tuvieron un único hijo, también llamado Paul, que nació en $1872^{1-4}$.

Sin embargo, gracias a la fortuna que le dejó su padre al morir, en 1886, 400.000 francos y su casa, Cézanne pudo, a partir de 1888, dedicarse sin apremios sólo a su arte. Esto contrasta completamente con la situación de gran parte de los artistas de esa época, salvo Toulouse- Lautrec, quienes sufrieron grandes apuros económicos ${ }^{1}$.

\section{Se relación con Émile Zola}

Cézanne mantuvo una estrecha relación de amistad con Émile Zola, que había empezado en la infancia cuando ambos asistían a la misma escuela básica en su tierra natal. Zola influyó positivamente a Cézanne para que desarrollara sus habilidades artísticas y fuera a París a perfeccionar su arte. Así Zola le escribió a Cézanne: "cobra pues nuevo valor, coge otra vez tu pincel y dale rienda suelta a tu fantasía. Yo creo en ti"1,3.

La correspondencia entre ambos es numerosa 
y Cézanne llegó a ser padrino de bodas de Zola. En 1886, la relación se rompió por Cézanne, quien se sintió ofendido por reconocer rasgos suyos en el personaje principal de la novela "La obra" de Zola, el artista Claude Lantier, quien acaba suicidándose. Zola, por otro lado, también ofendido, en una editorial de Le Figaro, reniega del valor artístico de Cézanne, llamándolo "un gran talento abortado". A pesar de esa aseveración, Zola conservó al menos una docena de cuadros de Cézanne ${ }^{1-4}$.

\section{El carácter de Cézanne}

Cézanne era de carácter huraño, hermético, taciturno, muy terco, perseverante, de maneras toscas y considerado como "mal educado" en

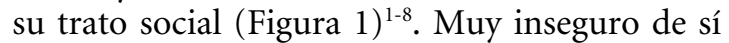
mismo, ironizaba y consideraba que se reían de él cuando era alabado por su arte. Era tal su inseguridad que demoraba demasiado en terminar una obra por constantes retoques a sus modelos humanos, que fueron muy escasos, los hacía posar incontables veces; por ejemplo, a su marchante Ambroise Voillard lo hizo posar 115 veces para un cuadro que no llegó a terminar ${ }^{1-5}$. A su esposa Hortense la retrató unas 25 veces durante un período de 20 años ${ }^{5,7-9}$, sin variar demasiado la postura. Pintó con muy pocos modelos por sus problemas de interrelación humana y patológica timidez con la mujer, no toleraba tener modelos mujeres desnudas y prefería pintar de imaginación los desnudos de sus cuadros. A Renoir le confidenció: "Yo pinto bodegones. Los modelos femeninos me asustan, todo el tiempo están al acecho para atacar por sorpresa" 1 .

Cézanne, a pesar de sus maneras toscas, era una persona de gran cultura, que podía recitar de memoria tanto versos en latín como lo más nuevo en literatura. El permanente alarde de inconformismo ha de ser interpretado como una protesta ante los convencionalismos, al que Cézanne trataba de contraponer una genialidad todavía muy incompleta e incomprendida.

\section{El arte de Cézanne}

Cézanne nunca se sintió cómodo en el ambiente de París, se sentía provinciano y prefería serlo. Su relación con los impresionistas fue ambigua, los criticaba esencialmente, pues para Cézanne el arte no pasaba por copiar la naturaleza sino expresar las emociones que la naturaleza motiva en el ser humano, develar la real esencia de la naturaleza. En esta búsqueda y necesidad de lograr algo nuevo se aparta de los impresionistas, si bien recibe importante influencia de Camille Pizarro y Claude Monet ${ }^{1}$. Pizarro, particularmente, le enseña a pintar al aire libre y se aprecia un notorio cambio en el colorido de los cuadros de Cézanne desde ese período. Monet expresó sobre Cézanne: "Qué mala fortuna que este hombre no haya contado con mejor apoyo en su experiencia. Es un artista auténtico, pero ha llegado tan lejos, que duda demasiado de sí mismo"1-4. Cézanne decidió, entonces, recluirse definitivamente en su ambiente natal, perfeccionarse y hacer su propio camino. Para Cézanne "pintar un cuadro significa componer... una gran sensibilidad es la disposición más propicia para una buena concepción artística". Cézanne fue en búsqueda, no de la luz como lo muestra la superficie de los objetos que fue la motivación de los impresionistas, sino la geometría como se vislumbra más allá de esa superficie. A través de variaciones del color objetiva los planos geométricos que él esperaba le permitirían mostrar la estructura de los objetos dando una masa y solidez que aumentaría su realidad. De los motivos habituales de los cuadros de Cézanne, sus bañistas, montañas, jugadores de cartas, su esposa Hortensia, quizás ninguna es tan familiar como las naturalezas muertas, especialmente sus manzanas: estas junto a jarros, botellas, manteles, se repiten una y otra vez (Figuras $2-4)^{1,7-9}$. El mismo Cézanne reconoce su predilección y mayor perfección en esta forma de representación artística y así se explica su frase de 1895 "asombraré a París con una manzana"1. Constituyen verdaderos cilindros, esferas y conos que crean la geometría de la naturaleza que deseaba mostrar. Cézanne logró reconocimiento en vida más por sus naturalezas muertas que por retratos o paisajes, a menudo considerados por la crítica más benévola como distorsionados y primitivos (Figura 5), sus bodegones rara vez dejaban impasibles a algún observador conocedor de $\operatorname{arte}^{1}$. Las obras de Cézanne, más que cuadros, reflejan pensamientos. La belleza, según Cézanne, tal como el alma de otra persona, no se puede poseer, solo puede apreciarse y para aquellos que tienen la voluntad, compartirla de 


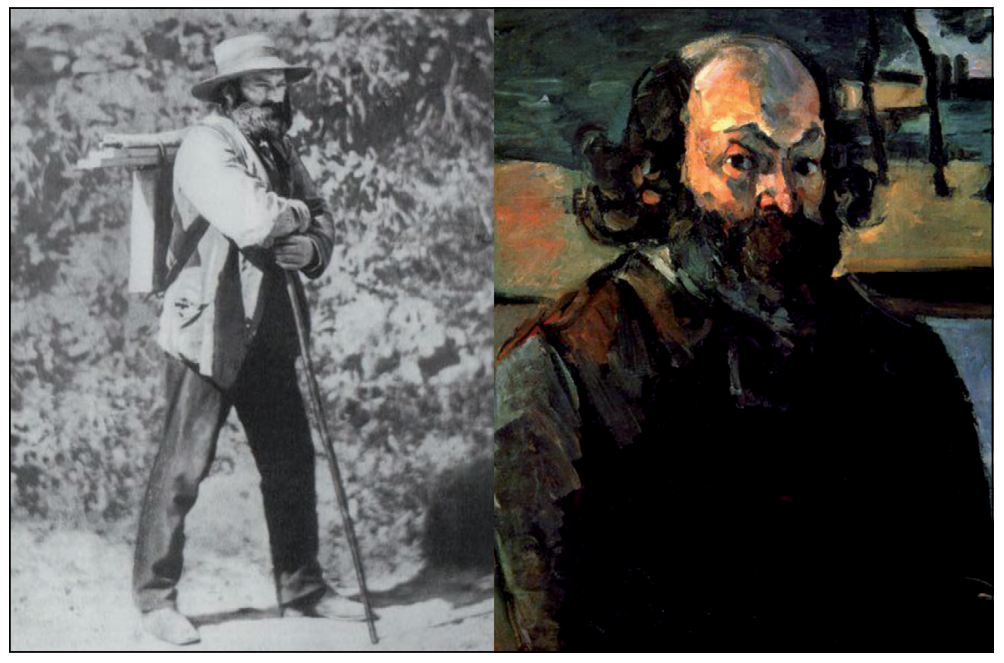

Figuras 1 . Tanto en la fotografía de Cézanne de 1874, a los 34 años, camino a pintar (A), como en el autorretrato de 1873-6, París, Museo de Orsay (B), es evidente, como en la mayoría de sus otros autorretratos, el rostro serio, atormentado del artista.

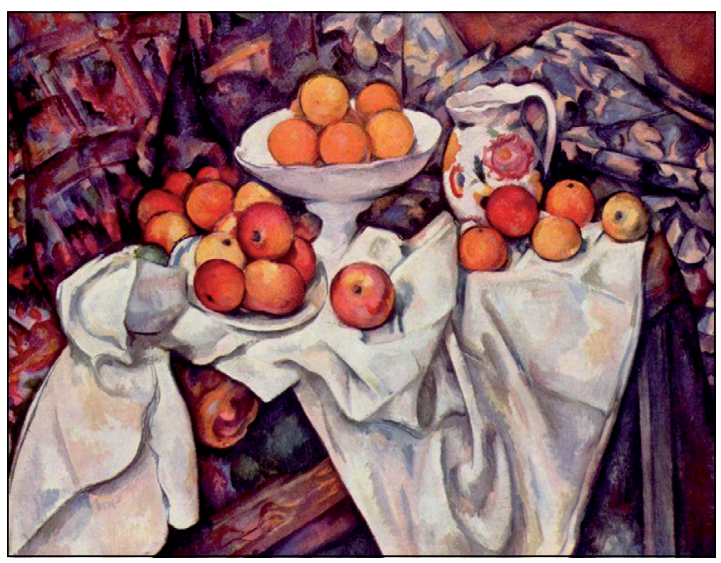

Figura 2. Figuras 2 a 4 muestran el extraordinario colorido de los bodegones de Cézanne Naturaleza muerta con manzana y naranjas.1895-1900. París, Museo de Orsay.

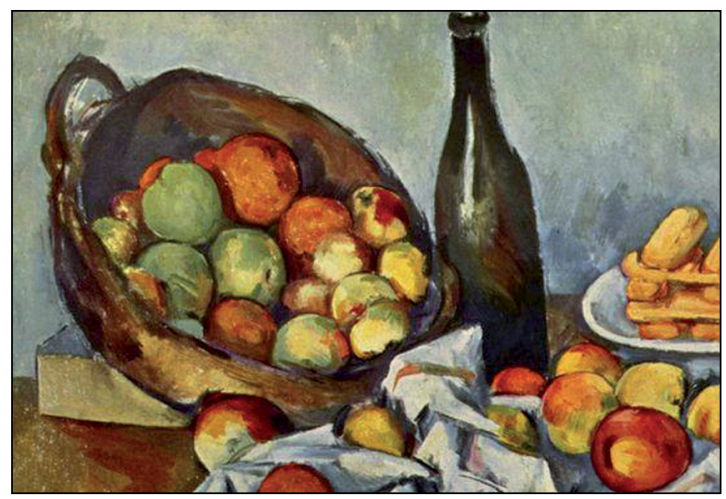

Figura 4. La cesta de manzanas. 1895. Helen Birch Bartlett Memorial Collection.

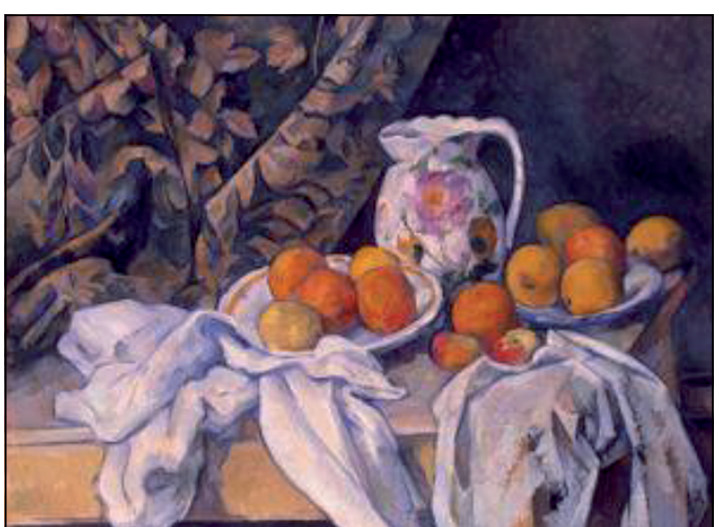

Figura 3. Naturaleza muerta con cortina, 1898-9. Museo del Hermitage, San Petersburgo.

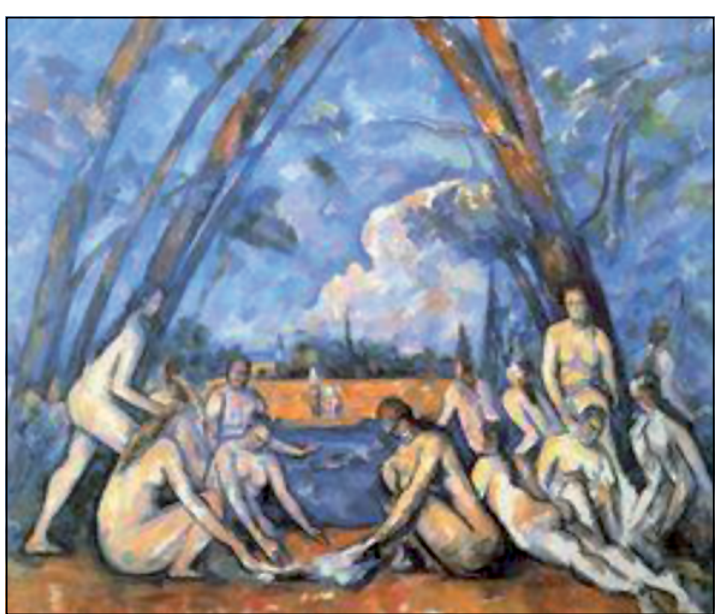

Figura 5. Los grandes bañistas. 1898-1905. Museo de Arte de Filadelfia. 
alguna manera misteriosa. Su visión, más allá del Impresionismo, queda reflejada en su afirmación: "quiero hacer del Impresionismo algo sólido y duradero, como el arte de los museos" y para esto decía que "recreaba al artista clásico francés Nicolas Poussin a través de la naturaleza", lo que implica su deseo de unificar su forma de observar la naturaleza con la permanencia de la composición clásica ${ }^{1,3,4}$.

Cézanne trató de expresar la totalidad de la forma, dando al objeto en su tela su real forma y volumen. Pintaba directamente, no dibujaba previamente, sus figuras eran modeladas prácticamente por la pintura. Modela con el color $\mathrm{y}$, a diferencia de los impresionistas, se adhiere al colorido natural. Sentía que la luz no podía sobreagregarse sino que ser producida por medio del mismo color. Creaba la impresión de líneas también a través del color. Hasta esa fecha, la representación del espacio había sido lograda por la perspectiva y claroscuros. Los impresionistas sacrificaron todo a la interpretación de la luz, Cézanne cambia este sistema al hacer la interpretación de la luz una forma de interpretar el espacio. Utilizó el color para representar la luz y sugerir volumen, mientras que con la correcta interpretación de los tonos consigue crear las formas ${ }^{1}$.

Joris-Karl Huysmans, poeta simbolista, quiso atribuirle a Cézanne un defecto visual a raíz de su particular falta de perspectiva en sus cuadros. Huysmans comentó respecto de las naturalezas muertas de Cézanne: "expuestas a plena luz sobre platos de porcelana o sobre manteles blancos, se ven peras y manzanas plasmadas en grandes trazos y modeladas con el pulgar; visto de cerca, el cuadro parece un desorden caótico de rojo vivo y amarillo, verde y azul. Más, si se guarda la distancia adecua$\mathrm{da}$, se convierten en frutas suculentas y jugosas que despiertan el apetito. Y de pronto, se percibe una verdad completamente nueva, nunca antes percibida, tonalidades extrañas y no obstante reales, manchas de color de una originalidad única, sombras que se proyectan por detrás de las frutas, sobre el mantel, mágicas en su colorido azulado apenas perceptible; todo esto hace de estas obras una revelación si se comparan con las naturalezas muertas habituales, ejecutadas en absurdos colores de asfalto"'.

En sus bodegones, los objetos podían rozarse y mezclarse, disolverse en la armonía del color y representar situaciones, de alguna manera como sustitución de la vida misma, a la que Cézanne no era capaz de enfrentarse. Cézanne pinta estas cosas sencillas con mucho amor y sentimiento, con una inimitable sensualidad, con una intensidad como ningún otro pintor lo había hecho excepto Jean Baptiste Chardin, admirado por Cézanne ${ }^{1}$. Las frutas que pinta Cézanne parecen tener el brillo de las frutas del paraíso, dice Cézanne al poeta Gasquet "he renunciado a las flores. Se marchitan rápidamente. Las frutas son más fieles. Es como si quisieran pedirte perdón por perder color. Su idea se exhala con su perfume. Llegan a ti en todos sus aromas, te cuentan de los campos que abandonaron, de la lluvia que las nutrió, de la aurora que las contempló. Cuando con toques pulposos de pincel se reproduce la piel de un hermoso melocotón, la melancolía de una manzana vieja, se puede entrever en los reflejos que ellos intercambian la misma sombra tenue de renunciación, el mimo amor del sol, el mismo recuerdo del rocío".

Para Cézanne "no existe ninguna línea, no existe ningún modelado, sólo existen los contrastes. Cuando el color alcanza su mayor riqueza, entonces la forma alcanza su plenitud"1,3,4.

Los cuadros de árboles que pintó al final de su vida documentan su manera poética de sentir la naturaleza. Estos árboles tienen un movimiento que parece venir de una dinámica que Cézanne percibía en todas las cosas: "He sentido un gran escalofrío. Si yo lograra, por el misterio de mis colores, comunicar este escalofrío a los otros, ¿no llegarán ellos a tener un sentido de lo universal, más obsesivo tal vez, pero cuanto más fecundo y más delicioso?... ¿ ¿los árboles como seres sensibles? ¿Qué hay en común entre los árboles y nosotros? ¿Entre un pino que se muestra ante mis ojos y uno tal cual es en realidad? Ah, si yo pintara eso. ¿ $\mathrm{No}$ sería ello la realización de un parte de la naturaleza, que el cuadro nos da al caer sobre nuestra mirada? ¡Los árboles como seres sensibles!”. "Yo quise copiar la naturaleza, pero claramente no lo logré. Más quedé satisfecho, en parte, conmigo mismo al descubrir que el sol, por ejemplo, no podía ser reproducido, sino que era indispensable representarlo por medio de otra cosa... con el color"1,3,4. Denis, biógrafo de Cézanne, plantea que toda obra de arte sería entonces "la transmisión... de una sensación recibida, o dicho de una manera más general, la transmisión de un hecho psicológico" 1 . 


\section{¿Cézanne como neurocientista?}

En sus últimos años y dando cuenta de cómo funcionaba su creación, Cézanne mencionó claros y sorprendentes conceptos neurológicos para esa época (fines siglo XIX) y para una persona sin estudios de medicina ${ }^{10}$. Cézanne afirmó en sus cartas al poeta Gasquet: "Hay 2 partes en un pintor que son básicas: los ojos y el cerebro; y ambas necesitan ayudarse mutuamente, tienes que trabajar en su mutuo desarrollo, pero a la manera del pintor; en los ojos mirando las cosas de la naturaleza; en el cerebro, por la lógica de sensaciones organizadas que dan los medios de expresión... los ojos deben concentrarse, fijarse, tomar el objeto, y el cerebro encontrará la forma de expresar esa información".

Los cuadros de Cézanne ilustran cómo él coordinaba su mente, cerebro, ojos y manos. La temática a que tantas veces recurrió en su vida, El Monte Santa Victoria, naturalezas muertas y bañistas, se ven $\tan$ frescos recreados en períodos de décadas, que nos permiten ver cómo la excepcional obra de Cézanne evolucionó a través de su vida de acuerdo a su capacidad de, primero decodificar lo que quería comunicar, y luego codificar estas percepciones y sensaciones en una pintura. Dos años antes de morir, Cézanne resumió su trabajo como artista en una carta a su amigo Louis Aurenche, diciendo: "Usted habla de mi realización en el arte. Creo que lo logro día a día, aunque un poco laboriosamente. Ya que, si el fuerte sentimiento por la naturaleza, y ciertamente lo tengo muy vívido, es una base necesaria para toda concepción artística en la cual descansa la grandeza y belleza de toda obra futura, el conocimiento de las formas de expresión de nuestras emociones no es menos esencial, y sólo se puede adquirir a través de una muy larga experiencia"10.

En palabras dichas al pintor Emile Bernard, un mes antes de morir, Cézanne reflejó su constante insatisfacción con lo logrado y su necesidad de seguir buscando: “ ¿alguna vez llegaré al final de lo que tanto he buscado por tanto tiempo?, espero que sí, pero hasta que lo obtenga, una vaga sensación de desasosiego me oprime y que no se irá hasta que llegue a puerto seguro, es decir, que haya logrado algo mejor que lo hecho en el pasado... así es que, continúo estudiando"8.

$\mathrm{El}$ arte de pintar puede interpretarse como un producto de nuestro cerebro, específicamente, como producto de toda la compleja circuitería neuronal que traduce una señal física, como la luminosa en conducta, experiencia y emoción. No corresponde acá revisar las vías involucradas que son bastante más que un receptor como la retina y un decodificador como la corteza visual y sus complejas conexiones con sistema límbico, áreas de asociación y sistema frontal ejecutivo. Esta maquinaria neural cerebral ha sido modelada por múltiples influencias, no sólo durante el desarrollo biológico, social y cultural del propio individuo, sino que también durante la evolución ${ }^{11}$.

Patologías que afecten distintos componentes de esta vía neuronal involucrada en el proceso artístico, desde la retina (retinopatía diabética como se plantea en Cézanne, degeneración macular en Degas, etc.), hasta enfermedades más difusas neurodegenerativas tipo demencia frontotemporal y Parkinson (siendo en esta última, en parte, debido a la terapia dopaminérgica), pueden sorprendentemente facilitar el proceso creativo en algunos artistas ${ }^{12-14}$.

Un aspecto que hace particularmente trascendente en la historia del arte a la producción artística de maestros, no sólo como Cézanne, sino también Monet y Matisse, es la importancia capital del manejo del color. La interacción dinámica que se produce entre el artista y su obra durante su producción está especialmente determinada por mecanismos de control visual y feed-back visual, para así regular el contraste de colores que, probablemente, determina en parte su originalidad y relevancia artística ${ }^{11}$.

Como ya mencionamos, al contrario de los artistas de la época, Cézanne no comenzaba sus cuadros con un dibujo, en cambio, él comienza inmediatamente con un color intenso y continúa desarrollando la imagen con parches de color distribuidos sobre la superficie de la pintura, así se logra discernir los objetos con claves, que son esencialmente colores. Con esta aproximación, Cézanne recluta a su sistema visual como medida del color exacto a usar ${ }^{11}$.

A partir de 1890, a los 51 años, se le declara una diabetes mellitus, que tendrá una seria descompensación en el año 1900 y, probablemente, contribuyó a los cuadros infecciosos respiratorios que motivaron su muerte ${ }^{1}$. Se ha planteado que Cézanne desarrolló como complicación una retinopatía diabética con ceguera parcial para colores azul-verde, lo que explicaría que su pintura cambiara a colores más tenues ${ }^{15}$. Se plantea que esta alteración oftalmológica sería responsable, en los 
últimos años de su carrera, de la transición del estilo de pintura a una más abstracta ${ }^{15}$.

Como otros maestros del Impresionismo, Cézanne fue también miope, pero rehusaba usar lentes, por considerarlos algo vulgar ${ }^{15,16}$. En cuadros de un mismo año, 1890, es posible ver naturalezas muertas pintadas a corta distancia muy nítidas y, a la vez, paisajes de larga distancia en que los detalles son borrosos y distorsionados, propios de alguien con miopía ${ }^{16}$.

La frustración fue evidente en la vida de Cézanne: mala relación con su padre, pobre relación de pareja y con su hijo, quienes preferían la vida de París, se enemistó con su mejor amigo de la infancia y en los últimos años de su vida recibió a muy pocas personas, entre ellas al pintor Émile Bernard y al poeta Gasquet. Su única relación perdurable y más satisfactoria, pero siempre con la sensación de estar imperfecta, fue con su obra artística.

Hay argumentos razonables para postular que la conducta de Cézanne podría ser descrita como lo que actualmente denominamos trastorno de personalidad límite. Su conducta podría ser explicada por la persistente inestabilidad en varios ámbitos que caracteriza a este cuadro, tanto en el estado de ánimo como en la autoimagen. Los episodios de ira y agresión manifiesta son frecuentes en este trastorno, especialmente cuando se presenta en varones. Los portadores de este trastorno típicamente establecen relaciones interpersonales inestables e intensas.

Un episodio que grafica estas características es lo ocurrido en 1895, cuando Monet organizó un pequeño homenaje, con otros colegas, a Cézanne, en su casa de Guiverny. Monet dijo en dicha ocasión: "al final estamos todos acá reunidos y valoramos la ocasión de decirte cuanto te queremos y cuanto admiramos tu arte". Cézanne, sorpresivamente, contestó rudamente: “¡Tú también te ríes de mí!”. Se dio media vuelta, tomó su abrigo y se retiró con un portazo ${ }^{17}$.

Esta hipersensibilidad, desconfianza, sentimientos de ser traicionado e irritabilidad son una constante en la vida emocional de Cézanne y se asemejan a las ideas de autorreferencia que los pacientes con este trastorno pueden presentar cuando se ven enfrentados a estrés.

Su creación fue muy poco reconocida, a pesar de dedicarle su vida entera. Literalmente le entregó la vida, ya que por estar pintando en el campo su última obra, que fue un retrato de su jardinero, fue sorprendido por una tormenta. Cae enfermo en cama, se levanta al día siguiente para intentar terminar su cuadro y es encontrado inconsciente. Se diagnosticó una neumonía, que le provoca la muerte el 22 de octubre de $1906^{1,3,4}$.

Realmente, Cézanne estaba intentando un imposible: crear sin abandonar la realidad y sin basarse en la imaginación. Sus últimas palabras, que reflejan descontento, son explicables, ya que no era un artista inventivo, sino un gran artista imaginativo, para quien era necesaria tener alguna visión de la realidad como punto de partida de su obra ${ }^{3}$.

\section{Referencias}

1. Duchting H. Paul Cézanne. La naturaleza se convierte en arte. Taschen, Colonia, 2003.

2. Torpy J. Portrait of Madame Cézanne. JAMA 2008; 299: 389.

3. Douglas L. Paul Cézanne. Burlingt Mag 1936; 69 (400): 32-5.

4. Southgate T. The Cover. JAMA 2003; 200: 993.

5. Southgate T. The Cover. JAMA 2005; 293: 1954.

6. Southgate T. Madame Cézanne in Blue. JAMA 1999: 281: 111-2.

7. Brion M. Paul Cézanne. Thames and Hudson, Londres. 1974.

8. Rewald J. Paul Cézanne: a biography. Abrahms H, New York. 1996

9. Rewald J. El postimpresionismo: de Van Gogh a Gauguin. Madrid. Alianza Editorial. Col. Alianza forma 31. 540. 1999.

10. Ione A. An Inquiry into Paul Cézanne. J Conscious Stud 2000; 7 (8-9): 57-74.

11. Conway B. Color consilience: color through the lens of art practice, history, philosophy, and neuroscience. Ann. N.Y. Acad. Sci. 1251 (2012) 77-94.

12. Miller BL, Ponton M, Benson DF, Cummings JL, Mena I. Enhanced artistic creativity with temporal lobe degeneration. Lancet 1996; 348: 1744-5.

13. Inzelberg R. The awakening of artistic creativity and Parkinson's disease. Behav Neurosci 2013; 127: 256-

14. Chatterjee A, Hamilton RH, Amorapanth PX. Art produced by a patient with Parkinson's disease. Behav Neurol 2006; 17: 105-8.

15. Ivaniševi $P$, Ivaniševi $M$. The influence of retinal eye diseases on painting. Coll Antropol 2015; 39 (1): 243-6.

16. Polland W. Myopic Artists. Acta Ophthalmologica Scandinava 2004; 2: 325-6.

17. Buckley PJ. Paul Cézanne (1839-1906). Am J Psychiatry $2011 ; 168$ (7): 680. 